\title{
Caracterização hidrogeomorfológica do entorno da jazida fósforo-uranífera de Itataia, Ceará, Brasil.
}

\author{
Hydro geomorphological characterization near the phosforo-uranium deposit of \\ Itataia, Ceará, Brazil.
}

\author{
MARANHÃO ${ }^{1}$, R.M.R.; LIRA², M.V.; SOUZA ${ }^{3}$, H.P.; DUARTE ${ }^{4}$, C.R.D.; SABADIA ${ }^{5}$, J.A.B. \\ rosamaranhao@gmail.com
}

\begin{abstract}
Resumo
A ocorrência de urânio e fosfato na Jazida de Itataia lança naturalmente radionuclídeos no ambiente através da ação erosiva dos ventos e da chuva. A importância econômica desse minério e os impactos relativos a sua mineração geram polêmicas em relação ao custo ambiental da atividade. A erosão superficial e o transporte de material está diretamente relacionado a amplitude e declividade dos relevos e dos materiais e processos envolvidos, desse modo a hidrologia tem papel preponderante no estudo dos transportes de contaminantes radioativos. $\mathrm{O}$ reconhecimento das feições do terreno é importante para determinar a estabilidade dos ambientes e o uso de geotecnologias tem facilitado a aquisição e tratamento de informações espaciais, colaborado com as pesquisas em gestão e monitoramento de usos. Desse modo essa pesquisa pretende disponibilizar informações sobre as feições do relevo, da drenagem e a definição do perímetro da sub bacia do Riacho Cunha Moti, Ceará, Brasil. Para o processamento foram utilizadas imagens SRTM 1Arc obtidas através de download gratuito e o software ArcGis 10. Os resultados gerados em cartogramas possibilitaram o reconhecimento dos fatores hidrogeomorfológicos que mais atuam para a dispersão de material radioativo no entorno da jazida.
\end{abstract}

Palavras-chave: urânio, dispersão, SIG.

\begin{abstract}
The occurrence of uranium and phosphate in the repository of Itataia launches naturally radionuclides in the environment through the erosive action of wind and rain. The economic importance of ore and the impacts of its mining generate polemics in relation to the environmental cost of the activity. The surface erosion and transport of material is directly related to the amplitude and steepness of the reliefs and the materials and processes involved, thereby hydrology plays an important role in the study of radioactive contaminant transport. The recognition of terrain features is important to determine the stability of the environment and the use of geotechnology has facilitated the acquisition and processing of spatial information, collaborated with research on management and monitoring uses. This research aims to provide information about the relief features, drainage and defining the perimeter of the sub basin of Cunha Moti river, Ceará, Brasil. For processing were used SRTM 1Arc images obtained via free download and ArcGis software 10. Results generated cartograms enabled the recognition of hydro geomorphological factors that act to the dispersion of radioactive material in the vicinity of the mine.
\end{abstract}

Keywords: uranium, dispersion, GIS.

\section{INTRODUÇÃO}

O urânio representa um recurso energético de grande interesse econômico e pesquisas para prospecção e mineração de urânio têm avançado, pressionados pela elevação do preço da uraninita $\left(\mathrm{UO}_{2}\right)$ no mercado internacional. O valor estratégico desse recurso é indiscutível, entretanto ainda existem grandes polemicas relativa ao uso da energia nuclear, frequentemente relacionadas com a questão do custo ambiental envolvido nas diversas etapas do processo de mineração até o produto

\footnotetext{
${ }^{1}$ Rosa Maria Ramos Maranhão, Departamento de Geologia/GEOCE, Universidade Federal do Ceara UFC, Fortaleza/CE, Brasil

${ }^{2}$ Maria Valdete Lira, Departamento de Geologia/GEOCE, Universidade Federal do Ceara UFC, Fortaleza/CE, Brasil

${ }^{3}$ Herdivânia Pires de Sousa, Departamento de Geologia, Universidade Federal do Ceara UFC, Fortaleza/CE, Brasil

${ }^{4}$ Cynthia Romariz Duarte, Departamento de Geologia/GEOCE, Universidade Federal do Ceara UFC, Fortaleza/CE, Brasil

${ }^{5}$ José Antonio Beltrão Sabadia, Departamento de Geologia/GEOCE, Universidade Federal do Ceara UFC, Fortaleza/CE, Brasil
} 
final. O interesse econômico aumenta quando o Urânio representa um subproduto associado a outro mineral. A prospecção de urânio no Brasil tem avançado nos últimos anos. As ocorrências uraníferas em maior escala estão nas jazidas de Poços de Caldas, em Minas Gerais, já explorada, Lagoa Real, em Caetité, na Bahia, já explorada, e a Fazenda Itataia, em Santa Quitéria, Ceará, ainda em fase de licenciamento, e representa a ocorrência do minério de maior interesse, na atualidade (PIRES, 2013). O Urânio é um elemento químico instável e seus dois isótopos naturais ${ }^{235} \mathrm{U}$ e ${ }^{238} \mathrm{U}$ dão origem a cadeia de decaimento radioativo. Sua distribuição e dispersão pela crosta terrestre estão associadas à atividade magmática, que facilita sua mobilidade desde a formação da Terra Primordial. O urânio é constituinte essencial de aproximadamente 100 minerais, ocorrendo principalmente na Uraninita, $\mathrm{UO}_{2}$. A solubilidade do urânio está relacionado à sua tendência em se oxidar em íons de $\mathrm{U}^{6+}$, sua mobilização natural no ambiente ocorre através do intemperismo da rocha, pela atuação da água contendo substancias húmicas, que atuam como poderosos agentes na mobilização de íons metálicos (BONOTTO \& SILVEIRA, 2006; PIRES, 2013).

A dinâmica dos rios e riachos no semiárido apresentam características marcantes em seu regime de descarga e transporte de sedimentos e na modelagem dos leitos, como resultado da sazonalidade das chuvas e ao intemperismo físico atuante e embasamento. A malha hidrográfica apresenta canais entrelaçados, devido ao controle estrutural, marcado por ocorrência de conjuntos de zonas de cisalhamento e falhas (MAIA et al, 2008), a litologia condiciona a presença de solos rasos e pedregosos e drenagem de leito pouco profundo e encaixado, com margens pouco definidas. Os maciços residuais apresentam vertentes de maior altimetria com declividades mais acentuadas e dissecadas. O intemperismo mecânico atuante provoca mobilização de material mais grosseiro e resistente (TAVARES et al, 2015). A vegetação esparsa, composta na maior parte por caatinga arbustiva aberta, não impede a ação erosiva dos ventos e da chuva, devido ao relevo levemente ondulado, a erosão laminar atua carreando sedimentos para as áreas de mais baixas (GONÇALVES JR e SOUZA, 2012). Os episódios de chuvas intensas em curto período de tempo sobre ocorrências de Urânio, como em nosso estudo, facilitam a dispersão natural pelo ambiente, no caso de chuva abundante (BONOTTO \& SILVEIRA, 2006), o fluxo superficial, ao atingir as margens planas e desprovidas de vegetação, como as que predominam os terrenos cristalinos, o fluxo mobilizador de sedimentos ultrapassa o leito, provocando forte movimentação de material (BATISTA et al, 2015; MAIA et al, 2008). As chuvas na região semiárida estão concentradas em poucos meses, janeiro a abril, com eventos de seca cíclicos, assim os processos mecânicos são mais atuantes em relação aos processos químicos, com formação de solos pedregosos e rasos, com drenagem difusa, em calhas pouco profundas. A mobilização de urânio no ambiente devido aos processos exógenos atuantes, como vento e chuva, no entorno da Jazida de Itataia, ocorre 
naturalmente, espalhando elementos radioativos, principalmente pelos vales de acumulação (drenagem), essa radioatividade ambiental é considerada uma medida backgroud, ou seja, está presente como parte das características daquele meio (BONOTTO \& SILVEIRA, 2006), entretanto a intervenção humana relativa a exploração desencadeia um desequilíbrio em virtude da abundancia de material radioativo lançado no ambiente. Desse modo a abordagem geossistêmica considera todas as relações biofísicas e humanas para compreender o funcionamento do todo refletindo sobre a abrangência dos impactos relativos a expansão das atividades humanas sobre o meio (DINIZ et al, 2015). Apenas como exemplo, ao observar os dados da FUNCEME no posto de Santa Quitéria, para os dias 17/3/2015 e 22/3/2015, apresentaram a marca de 53mm e 57,3mm de chuva respectivamente, o que comprova a ocorrência de grande volume pluviométrico concentrado, episódios dessa natureza eleva o risco potencial de erosão, facilitado que grande quantidade material seja mobilizado por longas extensões. Desse modo a percepção das relações do clima, regime pluvial, litologia, geologia e drenagem, na formação dos relevos, facilitam na compreensão dos ambientes e dos fatores que os tornam mais ou menos instáveis. (DINIZ et al, 2015; GONÇALVES JR e SOUZA, 2012).

O reconhecimento das feições da geologia estrutural e como camadas foram depositadas e alteradas pelas ações do paleoclima pelo longo tempo são fundamentais para compreender a fisionomia dos relevos e sua gênese. O embasamento muito antigo da área de interesse está presente e com zonas de cisalhamento e falhas que controlam estruturalmente os ambientes da porção central do Ceará. Os produtos resultantes variam de acordo com a litologia e geologia da área conferindo uma diferenciação qualitativa ao ambiente (MAIA et al, 2008; TAVARES et al, 2015). A declividade, a amplitude, tipo de perfil e as variações transversais são outras condicionantes morfogênicas do processo erosivo. Conforme Waltrick (2010) “A erosividade média anual é maior quanto maior a precipitação média anual e quanto maior for a variabilidade da chuva ao longo do ano. Nas regiões tropicais, mais de $40 \%$ das chuvas são consideradas erosivas, enquanto nas regiões de clima temperado, esse percentual é em torno de 5\%" (WALTRICK, 2010, apud BATISTA, 2015). A análise das variáveis morfométricas e dos modelos hidrológicos de uma área são capazes de apresentar um cenário onde é possível perceber a estabilidade dos ambientes e planejar ações para evitar impactos ambientais relacionados ao uso e ocupação do solo, tendo como unidade ambiental a bacia ou a sub-bacia. Por esta razão, os índices morfométricos podem fornecem informações de apoio ao planejamento das atividades econômicas, sendo possível reconhecer as inter-relações dos processos e as características quantitativas e qualitativas da bacia, como por exemplo, a susceptibilidade a ocorrência de cheias e a densidade e forma da drenagem (SANTOS et al, 2015). O manejo e a modelagem de bacias de drenagem requer o conhecimento 
específico de suas características físicas, como forma e dinâmica climática e evolutiva, sendo imprescindível a correta interpretação das estruturas geológicas e das feições geomorfológicas envolvidas na sua área de abrangência. A caracterização de uma bacia hidrográfica pode ser obtida através da análise dos modelos de elevação e dos vários planos de informação podem ser gerados em forma de novas imagens raster, obtidas através de processamento de algoritmos para reconhecimento de feições do relevo. (PAZ \& COLLISCHONN, 2008; SANTOS et al. 2015).

A análise geomorfológica pode ser realizada empregando-se diversos produtos digitais processados por sistemas computacionais. Mesmo com a disponibilidade desses produtos digitais, a extração da drenagem manual com a utilização de cartas topográficas ainda é muito utilizado, visto a confiabilidade desses dados. Com o avanço das técnicas de sensoriamento remoto, de softwares de processamento de imagens de satélite e dos sistemas informação geográfica (SIG), as funcionalidades avançaram e se automatizaram, empregando para tanto, métodos específicos para extração de informações geomorfológicas a partir de Modelos Digitais de Elevação (MDE) (BATISTA et al, 2015; FLORENZANO, 2008; SANTOS et. al, 2015). Florenzano (2008) salienta que, graças aos avanços tecnológicos, a geomorfologia tem a seu dispor um novo instrumental baseado em imagens com melhores resoluções espacial, espectral e temporal, geradas a partir de sensores ópticos e de radares interferométricos. A partir das imagens, com as inovações dos SIG, é possível visualizar o espaço geográfico em três dimensões, obtendo variáveis morfométricas essenciais nos estudos geomorfológicos, tais como dados de altitude, declividade, orientação de vertentes, áreas de acumulação, modelos de elevação, entre outras.

A integração de informação ambiental proporciona, quando analisadas sob o paradigma dos geossistemas, uma ampla visão das relações entre os vários fenômenos biofísicos e a ação humana expressa na ocupação e uso do solo visíveis nas transformações da paisagem, uma vez que todos os componentes do sistema se relacionam, seja por sub sistemas ou classes, qualquer alteração nos fluxos de matéria e energia em uma parte, vai impactar o todo (DINIZ et al, 2015), os resultados dessa análise devem ser a base para o planejamento e gestão ambiental.

Este estudo buscou aplicar técnicas de geoprocessamento para tratamento de imagem Shuttle Radar Topography Mission - SRTM, com resolução espacial de 30m e processamento computacional para extrair informações sobre o relevo e a drenagem. As imagens foram compostas por fusão de produtos obtidos entre as etapas do processamento, foram extraídos automaticamente dados vetoriais sobre a drenagem e depois comparados com a vetorização sobre a Folha Itatira, SB24-V-B-V, das cartas topográficas da SUDENE, também foi possível delimitar o perímetro da subbacia, identificar as feições relativas às estruturas de controle do relevo e realizar uma análise 
qualitativa relativa a direção de fluxo e sua relação com a dispersão de material radioativo no entorno da jazida de Itataia, Ceará, Brasil.

A região onde está inserida a jazida fósforo-uranífera de Itataia compõe-se por duas grandes unidades morfológicas: a Depressão Sertaneja e Planaltos Residuais. O polígono envolvente da área selecionada para este estudo está localizada ente as coordenadas: 950000, 40400 e 9486000, 42200 e corresponde à uma parte da porção SW do arco magmático de Santa Quitéria, na região centro-norte do Estado do Ceará. O potencial da jazida no município é caracterizado como um dos maiores do País e a única no mundo a possuir o minério de urânio associado ao fosfato (SILVA, 2004, PIRES, 2013). O principal corpo de minério ocorre numa elevação, com 800 metros de comprimento e largura variável entre 250 a 400 metros. O minério ocorre desde a superfície até a profundidade de 180 metros (SILVA, 2004). As reservas lavráveis do corpo principal são da ordem de 8.882.000 t de $\mathrm{P}_{2} \mathrm{O}_{5}$ e $79.319 \mathrm{t}$ de $\mathrm{U}_{3} \mathrm{O}_{8}$,

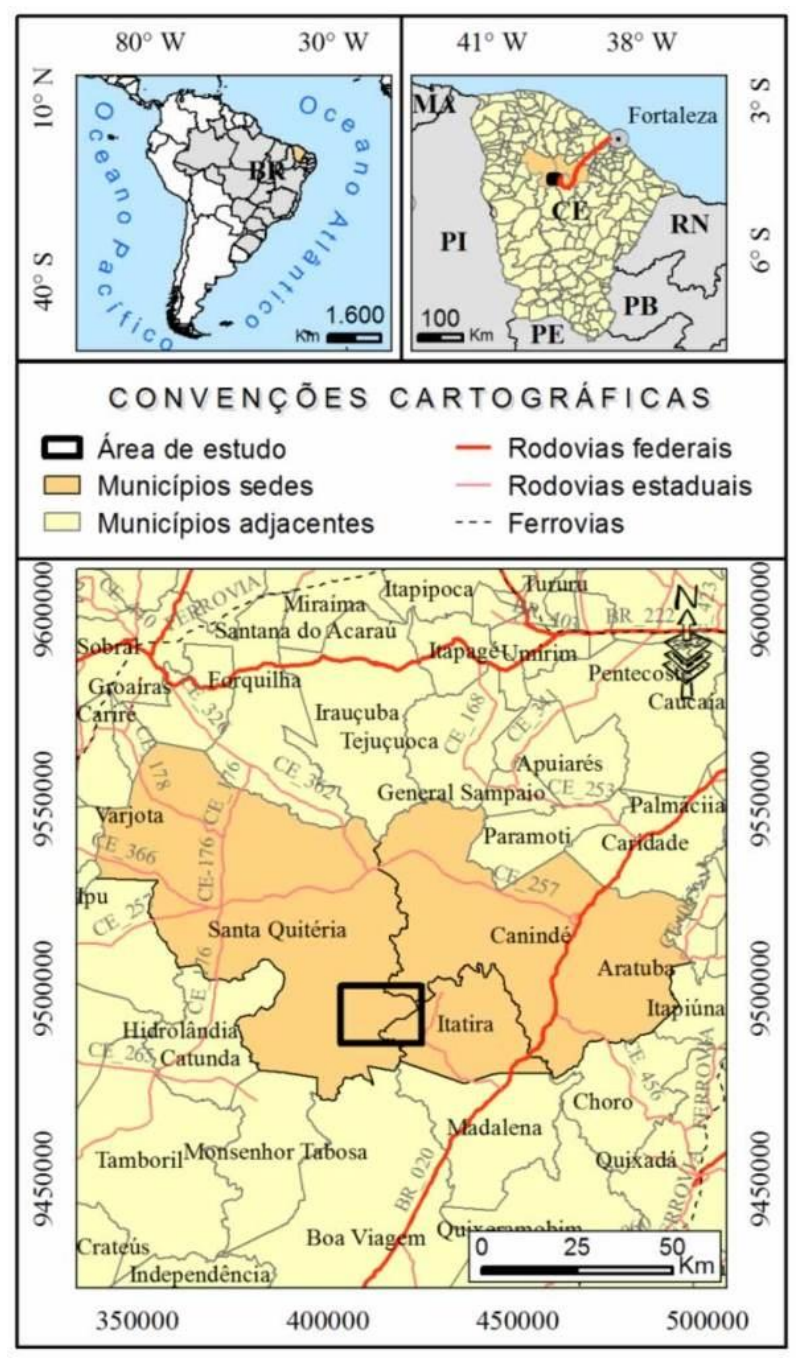

Figura 1 - Localização da área de estudos sendo 79.500.000 t de minério (figura 1). O potencial da jazida no município de Santa Quitéria é caracterizado como um dos maiores do País e a única no mundo a possuir o minério de urânio associado ao fosfato. A lavra será a céu aberto. (SILVA, 2004, PIRES, 2013).

A sub-bacia do Riacho Cunha Moti está localizada no alto curso da sub-bacia do Rio Groaíras, na bacia do Rio Acaraú, suas nascentes estão abrigadas na Serra do Céu, que é o divisor de outras duas bacias: Bacia do Curú e Sub-bacia do Banabuiú. As características da drenagem apresenta padrão difuso, de fluxo intermitente sazonal, com vegetação predominantemente de caatinga arbustiva aberta nas partes mais baixas e arbustiva fechada com presença de vegetação arbórea nos topos dos morros. O Serrote Verde, onde se encontra o minério, apresenta o topo com vegetação rala e dispersa, apresenta o colofanito associado ao urânio exposto, bastante desgastado pelos processos atuantes (figura 2). O serrote está localizado na porção central superior da imagem, entre a Serra do Céu e o açude. 


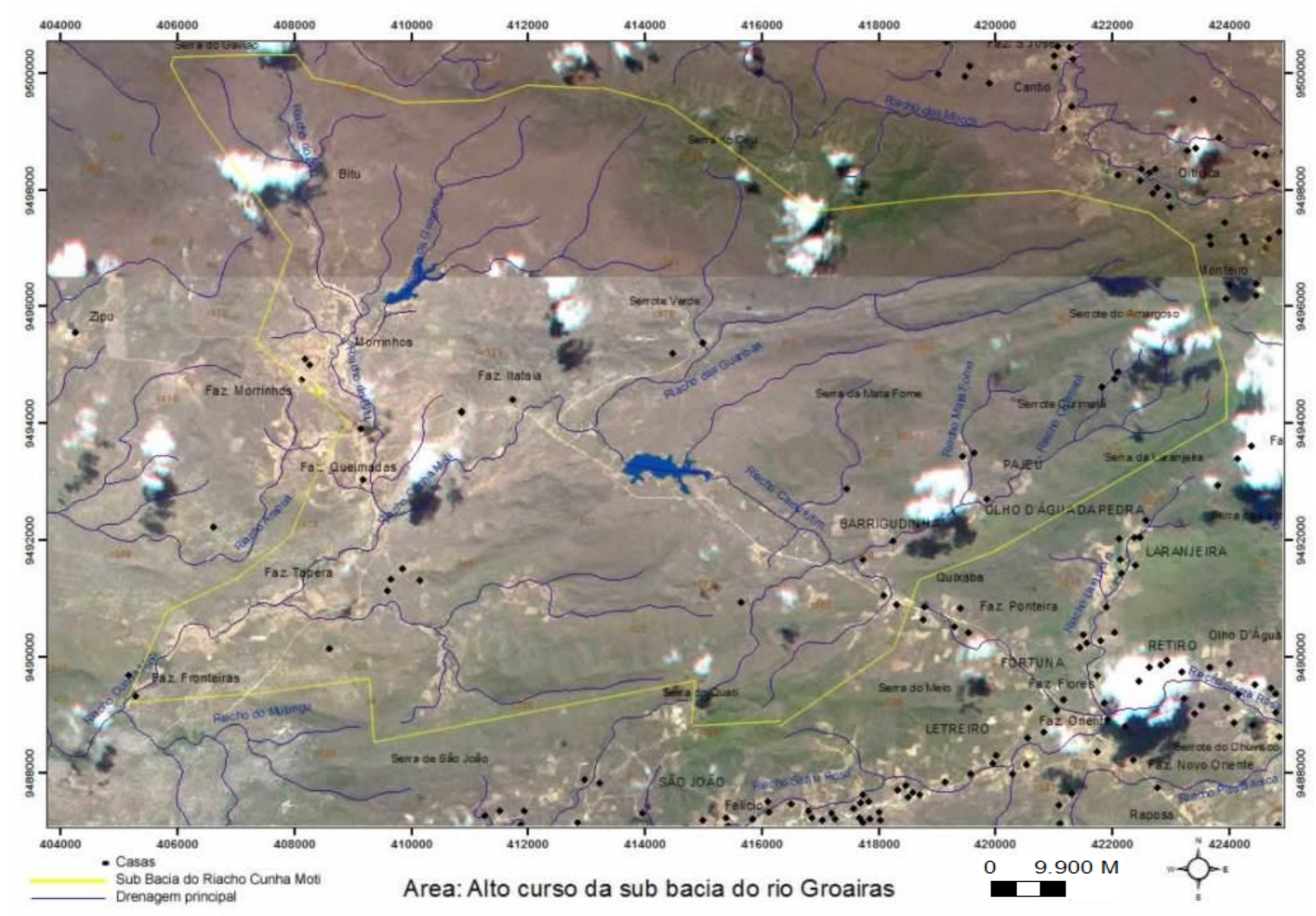

Figura 2 - Sub-bacia do Riacho Cunha Moti, Sub-bacia do Rio Groaíras, Ceará. Fonte: Elaboração Própria, 2016.

\section{METODOLOGIA}

Abaixo estão apresentados os quadros descritivos das imagens e do processamento realizado para obtenção dos dados para cartografia e análise das informações morfométricas da sub-bacia e a respectiva drenagem. Todo o geoprocessamento foi executado no software ArcGis 10.

Quadro 1 - Produtos de Sensoriamento Remoto

\begin{tabular}{|l|l|l|l|}
\hline Imagem & Id & Data & Fonte \\
\hline SRTM 1Arc 30m UTM 24S & s05_w040_1arc_v3.tif & 2014-09-23 & USGS/Earth Explorer \\
\hline
\end{tabular}

Quadro 2 - Arquivo de Vetorização

\begin{tabular}{|l|l|l|}
\hline Arquivo & Objetivo & Fonte \\
\hline Drenagem_Ce.shp & vetorizado da Folha SB-24-V-B-V, Itatira, 1:100.000 & SUDENE \\
\hline Limite.shp & polígono da área de estudos & Elaboração \\
Ȧrea da jazida.shp & representação da área da jazida e entorno imediato & própria \\
\hline
\end{tabular}

Quadro 3 Software ArcGis v.10

\begin{tabular}{|l|l|}
\hline \multicolumn{1}{|c|}{ Processamento } & \multicolumn{1}{c|}{ Comando } \\
\hline Recorte da área & Clip \\
\hline Correção da imagem & Fill e Sink (Hidrology) \\
\hline Análise do terreno & Aspect, Contour, Hillshade, Slope \\
\hline Extração da drenagem & $\begin{array}{l}\text { Flow accumulation, Flow Direction, } \\
\text { Watershed }\end{array}$ \\
\hline Delimitação da sub bacia & Basin \\
\hline
\end{tabular}




\section{RESULTADOS E DISCUSSÃO}

A integração dos planos de informação através de SIG gera produtos que servem de apoio a gestão ambiental, apresentando informações de forma sistêmica e integrada (DINIZ et. al, 2015). A partir da imagem SRTM 1Arc já corrigida, foram extraídas informações relativas a superfície do terreno e modelagem hidrológica, apresentados adiante. Como primeiro passo da análise do terreno está relacionada aos controles estruturais dos relevos, com a fusão do SRTM e o relevo sombreado foi possível reconhecer o embasamento fortemente fraturado e as falhas, identificamos as duas grandes unidades geomorfológicas, a Depressão Sertaneja, bastante dissecada e os relevos de altimetria aproximada de $1100 \mathrm{~m}$ dos Maciços Residuais. É possível reconhecer o padrão de drenagem difuso, com características marcantes do controle estrutural o que condiciona os vales de acumulação a um aspecto mais retilíneo, é possível o reconhecimento das feições dos canais e a direção do fluxo e o canal principal da sub bacia, na diagonal do canto superior direto para o canto inferior esquerdo, onde fica evidente a curva do encontro das falhas (BATISTA et al, 2015; MAIA et al, 2010).

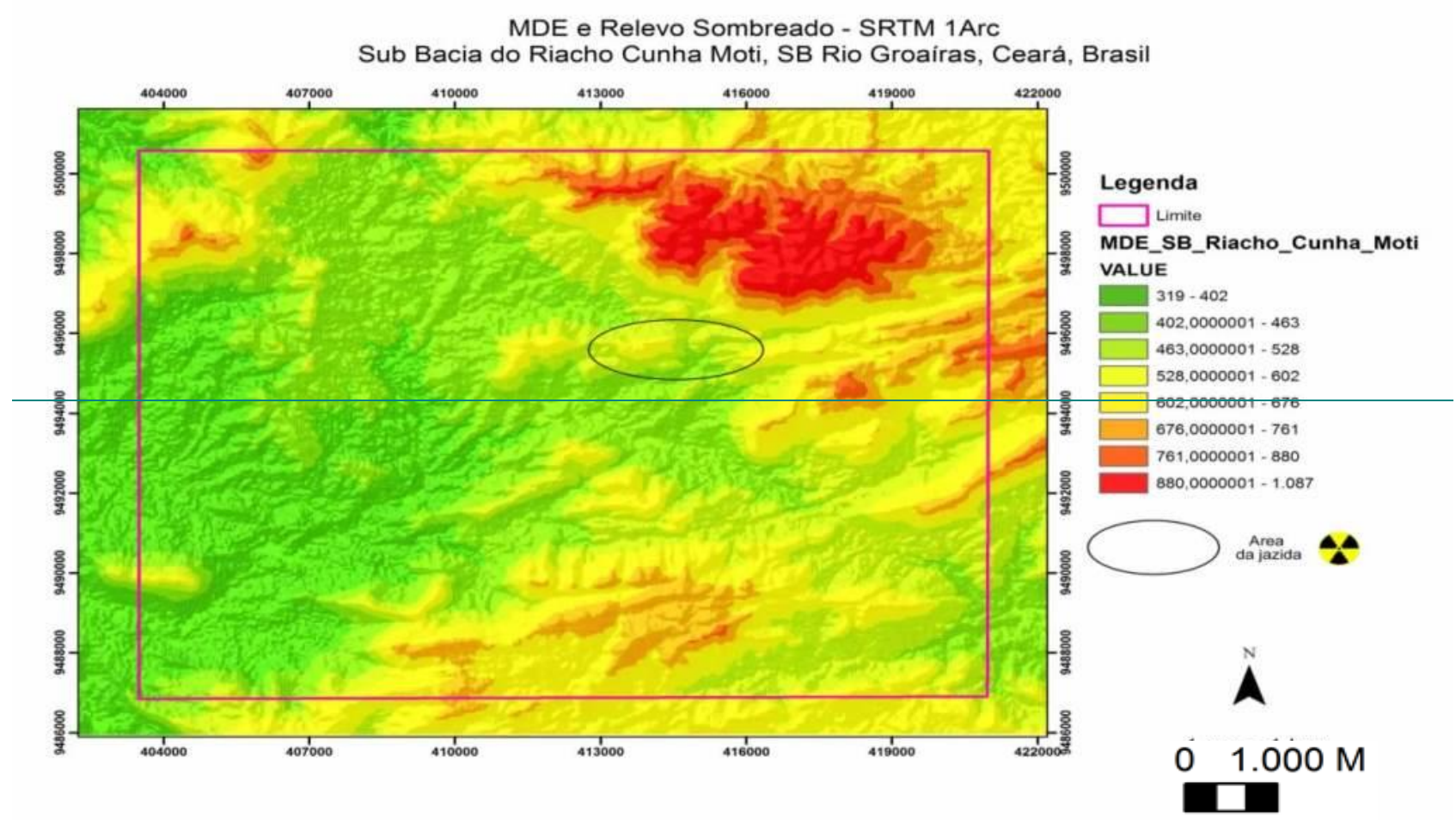

Figura 3 - MDE e Relevo Sombreado. Fonte: Elaboração Própria, 2016

O resultado da extração automática da drenagem pelo software em comparação com as linhas vetorizadas a partir da Folha Itatira, SB-24-V-B-V, Esc: 1:100.000, das Cartas Topográficas da SUDENE, apresentou melhor definição da drenagem, detectou canais que não foram descritos na carta e apresenta claramente os leitos encaixados. Certamente a precisão das informações fornecidas é uma grande 
contribuição das geotecnologias, associada à facilidade e rapidez, para produzir uma cartografia digital de qualidade (Figura 4).

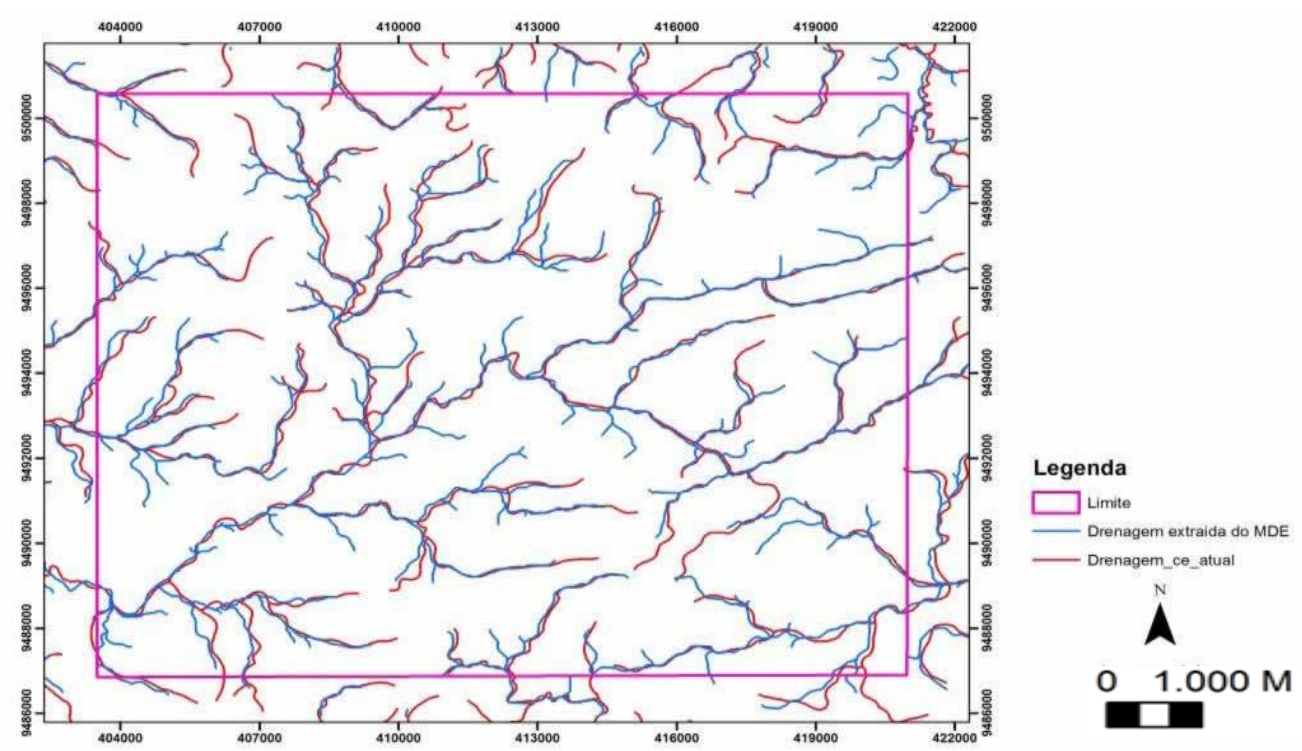

Figura 4 - Comparativo entre a drenagem vetorizada e a drenagem extraída do MDE. Fonte: Elaboração Própria, 2016

A sudoeste fica bem evidente a entrada do canal principal da sub-bacia no conjunto de fraturas que ligam a falha do Rio Groaíras circundando o relevo e se encaixando. As informações sobre a altimetria dos relevos o contraste entre as duas unidades do relevo da sub-bacia (figura 5).

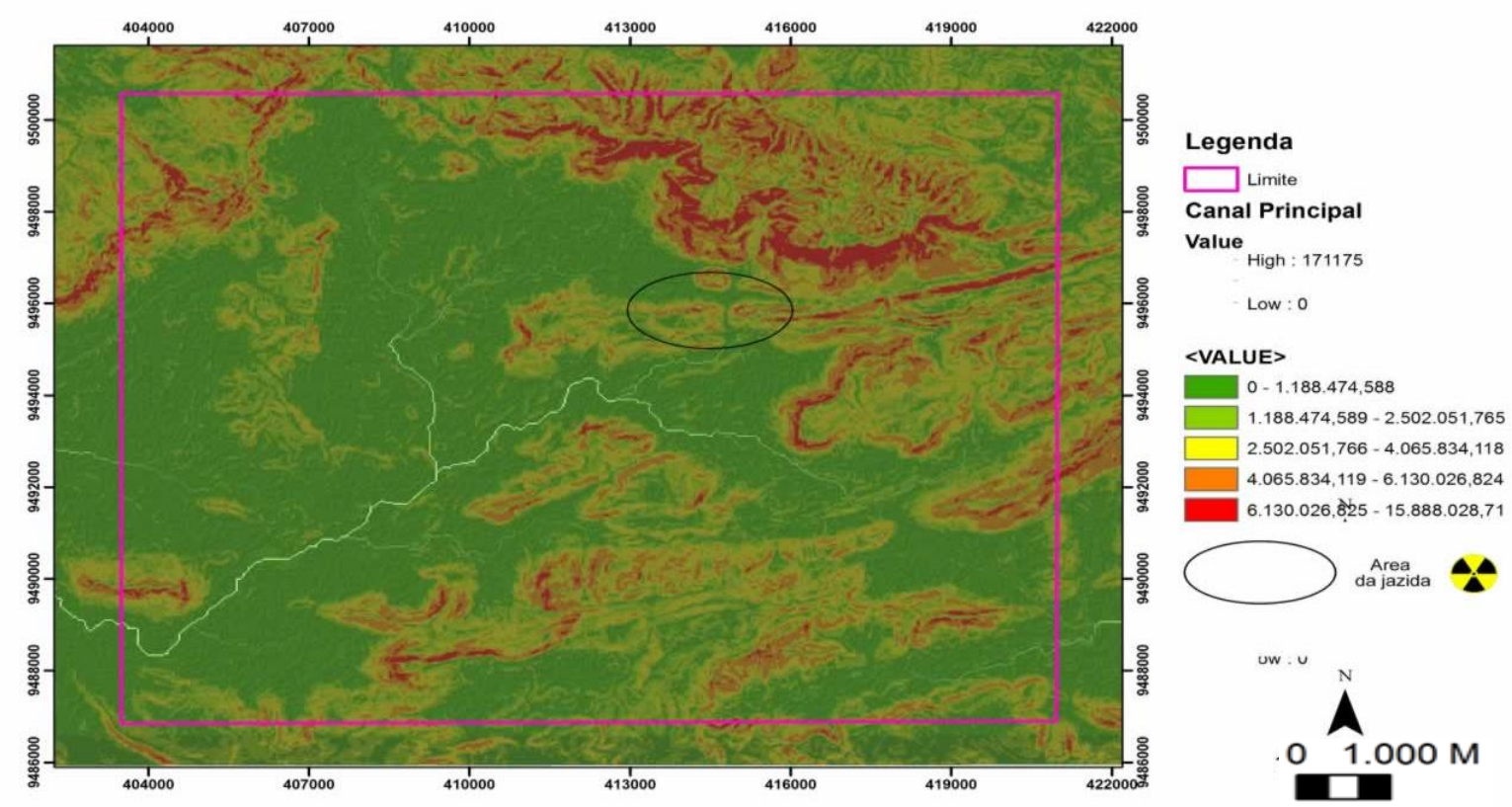

Figura 5 - Integração do relevo sombreado, das encostas e a área de acumulação, que é resultado das análises do fluxo superficial, resultam na apresentação d o canal principal da sub-bacia e o contraste dos relevos das áreas. Fonte: Elaboração Própria, 2016.

A figura 6 apresenta um produto em que os planos de informação integrados possibilitaram uma análise que pode subsidiar os planos de intervenção no entorno da Jazida. Quando lançamos mão da analise 
sistêmica para observar um fenômeno, a sobreposição das informações, suas relações e trocas de energia e matéria, são importantes elementos que interagem continuamente e devem ser observados sempre de forma integrada. A localização da jazida e sua relação com a drenagem propiciam ambiente favorável à dispersão de elementos radioativos devido aos intensos processos erosivos atuantes.

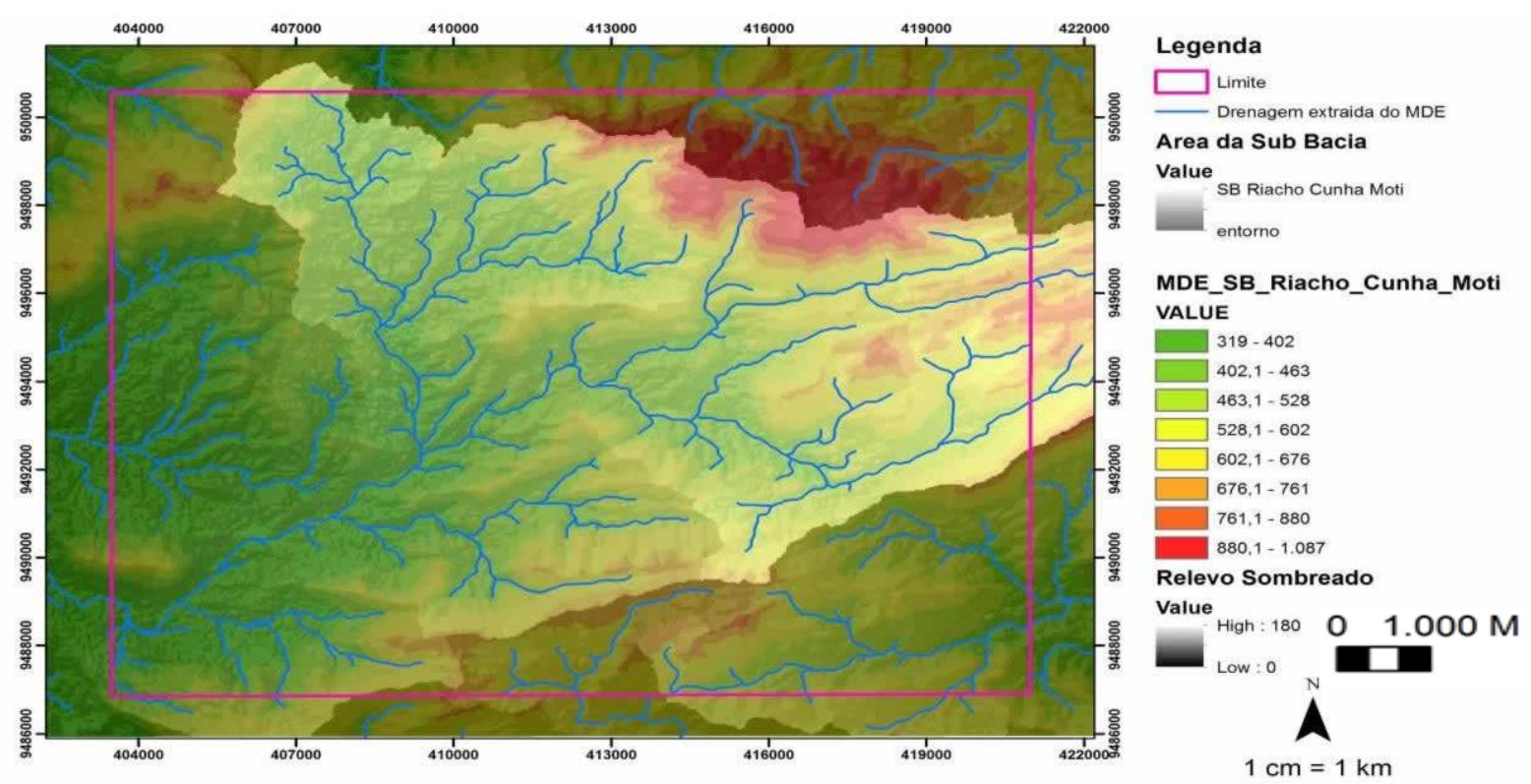

Figura 6 - Cartograma das informações sobre o relevo e a drenagem, indicando nas áreas mais elevadas, as áreas da sub-bacia mais elevadas, possível reconhecer o leito do Rio bem definido pelo controle estrutural das zonas de cisalhamento e falhas. Fonte: Elaboração Própria, 2016.

\section{CONSIDERAÇÕES FINAIS}

A presença da jazida fósforo-uranífera onde o colofanito está exposto no topo e nas encostas do relevo, proporcionando condições favoráveis para Mobilização de sedimentos radioativos por grande área por ação da água, em eventos de chuva intensa, ou pelo vento. As geotecnologias trouxeram muitos avanços à análise ambiental, facilitando a Produção de Planos de informação sobrepostos em cartogramas, possibilitando a Análise integrada de informações geográficas e assim servir de instrumento de apoio à tomada de decisão na gestão ambiental. A precisão, a facilidade e rapidez cada vez maiores, toram o geoprocessamento um instrumental imprescindível para os estudos espaciais.

\section{REFERÊNCIAS}

BATISTA, C. T.; VERÍSSIMO, C. U. V.; SANTOS, M. P. Avaliação do cálculo de erosividade em escala regional com o auxílio de geoprocessamento na Serra de Baturité - CE. Revista de Geociências do Nordeste, v.1, n.1. p. 22-36, 2015.

BOnOtTO, D. M., SILVEIRA, E. G. da. Geoquímica do Urânio. Aplicada a Águas Minerais. Editora UNESP, São Paulo, SP. 2006. 160 p. 
DINIZ, M. T. M.; OLIVEIRA, G. P.; MEDEIROS, D. B. S. Proposta de classificação das paisagens integradas. Revista de Geociências do Nordeste, v.1, n.1, p.50-65, 2015.

FlorenZano, T. G.. Geomorfologia. Conceitos e técnicas atuais. Oficina de Textos. São Paulo, SP. 2008. 320 p.

GONÇALVES JR, J. T., SOUZA, M.J.N. de. Caracterização Ambiental de Santa Quitéria, Ceará: A Nova Cidade Uranífera do Brasil. Revista Geonorte, Edição Especial, V.2, N.4, p.1368-1377. 2012.

MAIA, R. P.; BEZERRA, F. H. R.; CLAUDINO-SALES, V. Vales Fluviais do NE: Considerações Geomorfológicas. Revista OKARA: Geografia em Debate. v.2, n.2, Edição Especial II Simpósio de Geografia Física do Nordeste. p.177-189. 2008.

- Geomorfologia do Nordeste: Concepções Clássicas e Atuais Acerca das Superfícies de Aplainamento Nordestinas. Revista de Geografia. Recife: UFPE - DCG/NAPA, v. especial VIII SINAGEO, n.1, 2010.

PAZ, A.R.; e COLLISCHONN, W. Extração de rede de drenagem a partir de dados do SRTM. Revista Geográfica Acadêmica v.2 n.2. 2008. p. 84-95.

PIRES, F. R. M. Urânio no Brasil: geologia, jazidas e ocorrências. Vitrina Comunicação, Eletrobrás Eletronuclear, Rio de Janeiro, 2013. 299 p.

SANTOS, C. L.; WANDERLEY, L. S.; VITAL, S. R. O.; GIRÃO, O. Análise da suscetibilidade à ocorrência de enchentes e alagamento na bacia do alto/médio curso do rio Jaguaribe, João Pessoa/PB, a partir de características morfométricas extraídas de dados SRTM. Revista de Geociências do Nordeste, v.1, n.1, p.37-49, 2015.

SILVA, J. R. de A. e. Caracterização hidrogeológica da Jazida de Itataia-Ce. Anais XIII Congresso Brasileiro de Águas Subterrâneas. São Paulo, SP. 2004.

TAVARES, B. A. C.; BARROS , A. C. M.; CORREA, A. C. B. Intemperismo nas superfícies de cimeira do planalto da Borborema. Revista de Geociências do Nordeste, v.1, n.1, p.66-75, 2015.

\section{AGRADECIMENTOS}

Agradecemos a CAPES pelo apoio financeiro.

Recebido em: 14/08/2016

Aceito para publicação em: 01/10/2016 